Bull. Mater. Sci., Vol. 22, No. 3, May 1999, pp. 571-579. (C) Indian Academy of Sciences.

\title{
Environmental effects in iron aluminides
}

\author{
R BALASUBRAMANIAM \\ Department of Materials and Metallurgical Engineering, Indian Institute of Technology, Kanpur 208 016, India
}

\begin{abstract}
Iron aluminides based on the stoichiometric compositions of $\mathrm{Fe}_{3} \mathrm{Al}$ and $\mathrm{FeAl}$ exhibit poor room temperature ductilities due to hydrogen embrittlement (HE). The presence of surface passive films reduces HE. The reduction is due to the lower rate of hydrogen liberation on the surface of iron aluminides with a passive layer. Theoretical and experimental verification for this idea are provided. The effect of addition of passivity-inducing elements $\mathrm{Ti}, \mathrm{Zr}, \mathrm{V}, \mathrm{Nb}, \mathrm{Ta}, \mathrm{Cr}, \mathrm{Mo}, \mathrm{W}, \mathrm{Si}$ and $\mathrm{Ni}$ to $\mathrm{Fe}_{3} \mathrm{Al}$ on the thermomechanical and electrochemical behaviour has been outlined. The $\mathrm{Cr}$ - and $\mathrm{Ti}$-alloyed intermetallics exhibited significant room temperature ductilities. Microstructural studies of the alloyed intermetallics revealed that when the addition of passivity-inducing element results in the precipitation of brittle phases with Fe and $\mathrm{Al}$, they crack during the processing operation. The addition of oxygen-active elements on the embrittlement behaviour is also discussed. The effect of these additions on the potentiodynamic polarization behaviour and high temperature oxidation behaviour is also briefly addressed. Methods to minifize HE by the addition of elements that irreversibly trap hydrogen and that prevent recrystallization have also been discussed.
\end{abstract}

Keywords. Iron aluminides; passivity; hydrogen embrittlement; structure-property-processing correlation.

\section{Introduction}

Iron aluminides based on the stoichiometric compositions of $\mathrm{Fe}_{3} \mathrm{Al}$ and $\mathrm{FeAl}$ are candidate materials for high temperature applications due to their superior oxidation and sulphidation resistance. One of the impediments to the commercial application of iron aluminides is their poor room temperature ductility. This is due to their susceptibility to hydrogen embrittlement (HE) (Liu et al $1989,1990)$. Several methods have been proposed to minimize HE like oxide coatings (McKamey and Liu 1990) (to minimize hydrogen pick-up from the environment), heat treatments (McKamey and Pierce 1993) (to produce a partially recrystallized microstructure) and alloying with passivity-inducing elements (Balasubramaniam 1996, 1997) (which provide a passive layer on the surface of the intermetallic that reduces hydrogen liberation rates on the surfaces and thereby minimizes hydrogen entry). Environmental effects in iron aluminides is addressed in the following sections. Although HE of iron aluminides would be focused, the communication would also address the room temperature aqueous corrosion and high temperature oxidation of $\mathrm{Fe}_{3} \mathrm{Al}$-based iron aluminides.

\section{Relationship of hydrogen liberation rate to embrittlement}

One of the major limitation of applying iron aluminides commercially is their poor ductility at ambient temperatures, which has been attributed to hydrogen embrittlement
(Liu et al 1989, 1990). The moisture-induced hydrogen embrittlement of iron aluminides has been the subject of several studies and the subject has been critically reviewed (Liu and Kumar 1993; Stoloff and Duquette 1990). One of the effective ways of minimizing $\mathrm{HE}$ in iron aluminides is by alloying with $\mathrm{Cr}$ (McKamey et al 1988). Additions of $\mathrm{Cr}$ as low as $2 \%$ have produced significant improvements in ductility of binary iron aluminides.

The role of chromium in minimizing the room temperature hydrogen embrittlement in iron aluminides has been critically addressed. It has been theoretically proposed that $\mathrm{Cr}$ induces passivity; in the aluminide and this reduces hydrogen evolution rates on freshly created surfaces to a very low value compared to unalloyed iron aluminides (Balasubramaniam 1996). The low hydrogen evolution rates on $\mathrm{Cr}$-alloyed $\mathrm{Fe}_{3} \mathrm{Al}$ results in a lower amount of hydrogen entering into the lattice, thereby minimizing embrittlement. This philosophy has been theoretically explained based on the mixed potential theory as provided in figure 1 (Balasubramaniam 1996). Moreover, an alloy development philosophy to produce ductile iron aluminides has been outlined, based on this theory (Balasubramaniam 1996, 1997).

In the original paper explaining the role of chromium in minimizing room temperature embrittlement due to hydrogen (Balasubramaniam 1996), the anodic polarization curves for $\mathrm{Fe}_{3} \mathrm{Al}$ and $\mathrm{Fe}_{3} \mathrm{Al}+\mathrm{Cr}$ were shown as exhibiting active and active-passive behaviour, respectively. The different rates of hydrogen evolution on the two materials were obtained by the intersection of the cathodic reduction line with the anodic polarization 
curve of $\mathrm{Fe}_{3} \mathrm{Al}$ in the active region, and with that of $\mathrm{Fe}_{3} \mathrm{Al}+\mathrm{Cr}$ in the passive region (figure 1). It can be noticed from this figure that the rate of hydrogen liberation (which is also equal to the rate of corrosion) is lower in the case of Cr-alloyed intermetallic due to the intersection of the reduction line in the passive region of the polarization curve in the case of this intermetallic. Moreover, the overpotential for hydrogen reduction reaction is much lower in the $\mathrm{Cr}$-alloyed intermetallic compared to the base aluminide and this implies that the partial pressure of hydrogen that is liberated on the surface of the former is much lower than in the case of the latter. The cathodic reaction was implicitly assumed to be the hydrogen evolution reaction, which results in $\mathrm{H}$ entry into the material, causing embrittlement. The role of the oxygen reduction reaction was also considered in a subsequent paper and the potentiodynamic polarization curves of $\mathrm{Fe}_{3} \mathrm{Al}$ and $\mathrm{Fe}_{3} \mathrm{Al}+\mathrm{Cr}$ were deciphered theoretically (Mukherjee and Balasubramaniam 1996). It was seen that the oxygen reduction reaction is important in passivity induction for the $\mathrm{Cr}$-alloyed iron aluminide, whereas it does not have a significant effect on the cathodic polarization curve in the case of the binary aluminide.

The theoretical interpretation of the polarization diagrams of the $\mathrm{Fe}_{3} \mathrm{Al}$ and $\mathrm{Fe}_{3} \mathrm{Al}+\mathrm{Cr}$ have been verified by potentiodynamic polarization experiments (figure 2 ). These results provide strong indications that the hydrogen liberation rate is the deciding factor in determining the role of surfaces on hydrogen embrittlement. In this regard, it is interesting to review some of the recent

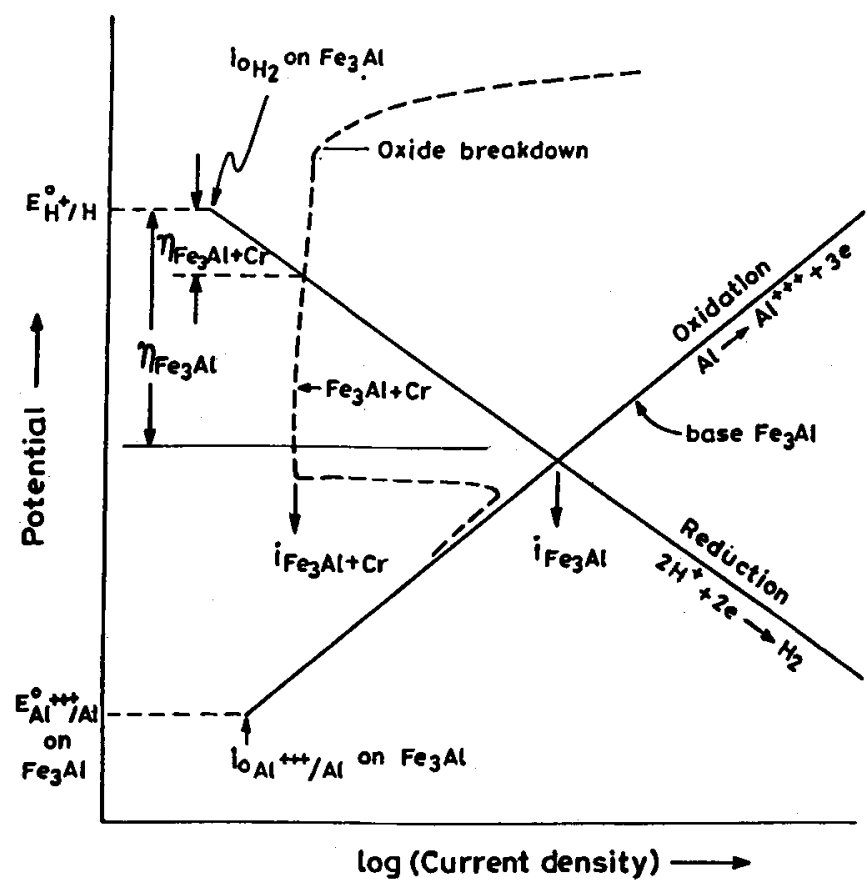

Figure 1. Mixed potential analysis of hydrogen liberation rates on surfaces of iron aluminide with and without $\mathrm{Cr}$. results published in the literature on this topic. Although nickel aluminides are different from iron aluminides, a recent study by Lee et al (1996) provides some significant clues on the similarity of HE phenomenon in these two class of intermetallics. It has been shown experimentally by Lee et al (1996) that hydrogen liberation rates on the surfaces of $\mathrm{Ni}_{3} \mathrm{Al}$ play a deciding role in the hydrogen embrittlement on these class of aluminides. They determined the rate of hydrogen liberation on both pure $\mathrm{Ni}_{3} \mathrm{Al}$ and boron-doped $\mathrm{Ni}_{3} \mathrm{Al}$ 'by fracturing the alloys in a ultra high vacuum fracture chamber attached to a Auger electron spectroscopy unit. Different low partial pressures of moisture in the fracture chamber were used in the study. It was clearly shown that the rate of hydrogen liberation was lower on the boron-doped nickel aluminide than that on the nickel aluminide. This was determined based on the height of the oxygen peak that was obtained by Auger spectroscopy. It is therefore evident that the rate of hydrogen liberation is lowered significantly in the boron-doped $\mathrm{Ni}_{3} \mathrm{Al}$ and in this way the embrittlement due to hydrogen is reduced on boron addition. It was earlier thought that the effect of boron on improving ductility (i.e. lowering hydrogen embrittlement) was related to the lowering of hydrogen diffusivity through the grain boundaries of the boron-doped $\mathrm{Ni}_{3} \mathrm{Al}$ due to trapping of hydrogen by boron present at the grain boundaries and also by enhancing the grain boundary cohesive strength (Liu and Kumar 1993).

In case the lower rate of hydrogen liberation is responsible for the lower degree of hydrogen embrittlement,

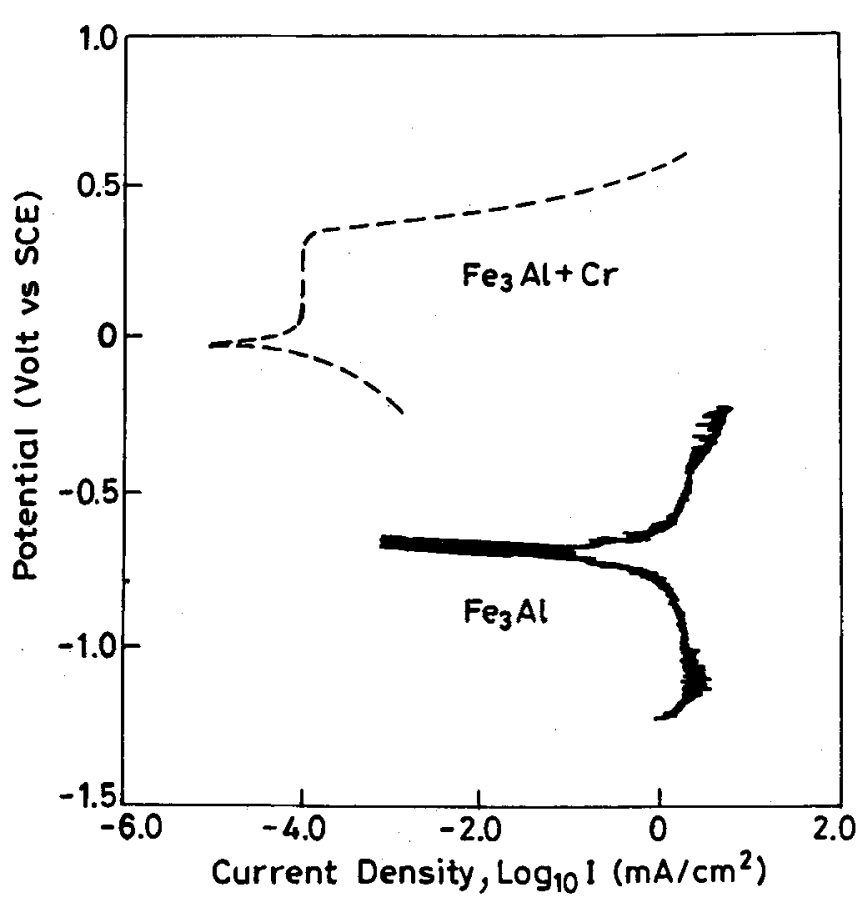

Figure 2. Experimental potentiodynamic polarization curves for iron aluminides with and without $\mathrm{Cr}$. 
it is possible to visualize that the effect of passivation on the ductility would be significant during initial exposure to the environment; but with continued exposure, there would be sufficient hydrogen pick-up in the material due to continued hydrogen liberation on the surface. In such a case, even a material on whose surface the hydrogen liberation rate is low would be susceptible to hydrogen embrittlement if it is exposed for a sufficient time in the environment. Therefore, it is anticipated that even $\mathrm{Cr}$-alloyed iron aluminides would be susceptible to embrittlement if they are exposed to the environment for longer times. It is only when tensile testing is performed immediately that $\mathrm{Cr}$-alloyed iron aluminides provide ductility, because in the short time of the tensile test the entry of hydrogen would be minimal due to low hydrogen liberation rates. In this regard, the recent experimental results of Tu et al (1998) are very revealing. They first completely removed hydrogen from $\mathrm{Fe}-28 \mathrm{Al}$ and $\mathrm{Fe}-28 \mathrm{Al}-5 \mathrm{Cr}$ by anodic polarization. The specimens were then immediately electrochemically charged with hydrogen and tensile tested. Their results on the ductility as a function of hydrogen charging time are presented in figure 3. It is seen that with increasing charging time, the ductility of both the $\mathrm{Cr}$-containing and $\mathrm{Cr}$-free iron aluminides are almost identical. The major difference is noticed only for the initial condition, i.e. for no charging. It is quite evident that when hydrogen is forced into the iron aluminide, it does not matter whether it contains the passive layer or not and in both the cases, hydrogen is able to permeate through the passive layer and enter the lattice to cause embrittlement. The beneficial effect of addition of $\mathrm{Cr}$ in minimizing the embrittlement is realized in testing done without hydrogen charging (i.e. when hydrogen enters the lattice by the moisture-induced oxidation of Al leading to alumina formation and sub-

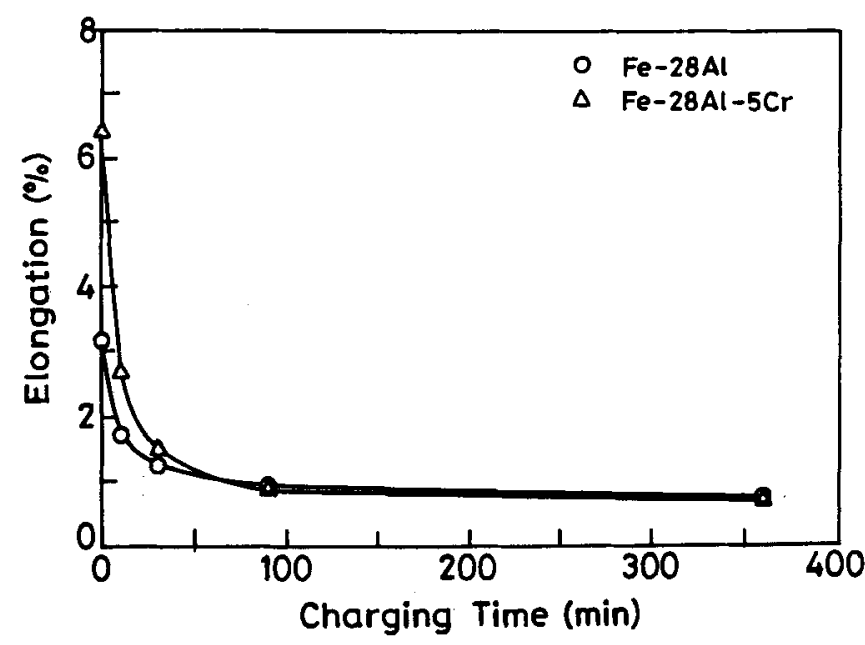

Figure 3. Variation of ductility of $\mathrm{Fe}-25 \mathrm{Al}$ and $\mathrm{Fe}-28 \mathrm{Al}-5 \mathrm{Cr}$ as a function of hydrogen charging time (Tu et al 1998). sequent hydrogen generation). The increased ductility obtained with the Cr-alloyed iron aluminide can be related to the lower rate of hydrogen liberation on the surface of this aluminide. Therefore, the surface layer acting as an effective barrier to hydrogen entry can be discounted.

The passive layers on iron aluminides have not been characterized in detail. However, Yangshan et al (1996) performed X-ray photoelectron spectroscopy (XPS) and determined the surface oxide composition of iron aluminides with and without $\mathrm{Ce}$. It was clearly shown that the constituents of the scale were chromia, iron oxide and alumina in both the cases. With the addition of $\mathrm{Ce}$, the percentage of chromia and alumina in the scale increased and this is due to the addition of $\mathrm{Ce}$, an oxygen active element which changes the oxide composition and properties. We shall later address the addition of oxygen active elements on the environmental degradation behaviour of iron aluminides. However, the purpose of the above discussion is to show that the oxides that form on the surface of iron aluminides are stable oxides and it cannot be reduced by electrochemically charging with hydrogen. The alloy tested by $\mathrm{Tu}$ et al (1998) also contained $\mathrm{Ce}$ in addition to $\mathrm{Zr}$ and $\mathrm{B}$. This implies that the passive layer on the surface of the iron aluminide do not provide hindrance to the entry of hydrogen into the lattice and if at all they do, it could be significant only in the initial stages. The oxides on the surface of the iron aluminides at high temperatures are relatively open with cracks in them (Babu 1998). Although this behaviour may not be the same on room temperature exposure, it nevertheless provides a clue that the cracks in the oxides on the surface of iron aluminides could provide short diffusion paths for hydrogen to enter the lattice. Moreover, the diffusivity of hydrogen has been determined by several investigators. The diffusivity of hydrogen in $\mathrm{Fe}_{3} \mathrm{Al}$ (Banerjee and Balasubramaniam $1998 \mathrm{~b}$ ) is higher than in FeAl (Banerjee and Balasubramaniam 1997). This could possibly be related to the higher $\mathrm{Al}$ content in the $\mathrm{FeAl}$ lattice, providing antitrapping sites thereby reducing hydrogen diffusivity. Therefore, it is important to note that the deciding factor in determining the effect of alloying is the way it affects the hydrogen liberation rates on the surface of the aluminides.

All the above discussions are equally applicable to FeAl-based intermetallics. However, there is one major difference in their mechanical response when compared to $\mathrm{Fe}_{3} \mathrm{Al}$-based intermetallics. The grain boundaries of $\mathrm{FeAl}$ are inherently weak and therefore these intermetallics fail by brittle intergranular failure. This factor overrides the environmental effect in the case of binary FeAl aluminides. However, when the grain boundaries are strengthened by $B$ additions, the environmental effect due to hydrogen is realized (Liu and George 1990). 


\section{Alloy development efforts}

Some salient features of iron aluminide alloy development activities pursued at IIT, Kanpur would be discussed in the following sections.

\subsection{Passivity induction}

We had earlier described that alloying additions that induce passivity in iron aluminides could be added to induce ductility. In such a case, the passive surface layer that forms in the environment would lower hydrogen liberation rates and thereby minimize hydrogen embrittlement. In view of the beneficial effect of surface passive films in lowering $\mathrm{HE}$ of iron aluminides (Agarwal and Balasubramaniam 1996a), an alloy development philosophy was proposed wherein it was stated that elements that induce passivity in iron when added to $\mathrm{Fe}_{3} \mathrm{Al}$ would inhibit hydrogen reduction and also its entry by maintaining a passive layer (Balasubramaniam 1996, 1997).

Several passivity-inducing elements $(M=T i, Z r, V$, $\mathrm{Nb}, \mathrm{Ta}, \mathrm{Cr}, \mathrm{Mo}, \mathrm{W}, \mathrm{Si}$ and $\mathrm{Ni}$ ) were alloyed to the base $\mathrm{Fe}_{3} \mathrm{Al}$ intermetallic (to produce $\mathrm{Fe}-24 \mathrm{Al}-5 \mathrm{M}$ intermetallics) in order to test the ductility enhancement philosophy (Agarwal et al 1996b). $\mathrm{Ni}$ could not be alloyed due to a violent reaction with the intermetallic on mixing, which is possibly due to the large exothermic heat of mixing between $\mathrm{Ni}$ and Al (Sikka 1994). Electrochemical polarization studies of the alloyed intermetallics in acidic $0.05 \mathrm{~mol} / 1 \mathrm{H}_{2} \mathrm{SO}_{4}$ solution indicated that the alloyed intermetallics generally induced passivity to the base iron aluminide (Agarwal et al 1996b; Banerjee and Balasubramaniam 1999). The base iron aluminide exhibited active corrosion in this medium. Therefore, passivity enhancement due to the addition of these elements has been verified. The base $\mathrm{Fe}_{3} \mathrm{Al}$ (Agarwal et al 1996a) and the alloyed intermetallics (Agarwal et al 1996b) were thermomechanically processed at $1000^{\circ} \mathrm{C}$ by multipass rolling after a homogenization treatment. It was observed that only the $\mathrm{Fe}-25 \mathrm{Al}, \mathrm{Fe}-24 \mathrm{Al}-5 \mathrm{Cr}$ and $\mathrm{Fe}-24 \mathrm{Al}-5 \mathrm{Ti}$ intermetallics could be rolled successfully to $80 \%$ deformation in multiple passes at $1000^{\circ} \mathrm{C}$. The Fe-24Al-5Ta intermetallic cracked after 50\% deformation and the Fe-24Al-5Nb intermetallic cracked after $40 \%$ deformation. The Fe-24Al-5Mo, Fe-24Al-5Si and Fe-24Al-5V could not be rolled as they cracked in the first rolling pass itself. Thermomechanical processing of the intermetallic is also an important aspect of alloy development as the material should be amenable to deformation processing from a commercial angle. Therefore, although the alloy additions induced passivity in the base intermetallic, they were not effective in enhancing ductilities. The poor thermomechanical response of the intermetallics alloyed with $\mathrm{Ta}, \mathrm{Nb}, \mathrm{Mo}, \mathrm{Si}$ and $\mathrm{V}$ was investigated. X-ray diffraction analysis of the alloyed intermetallics revealed that $\mathrm{Cr}$ and $\mathrm{Ti}$ additions to binary $\mathrm{Fe}_{3} \mathrm{Al}$ enter into solid solution without forming any new phase(s) or precipitates (Agarwal and Balasubramaniam 1996b). The ductility enhancement obtained with these additions is due to both passivity enhancement and the elements remaining in solid solution when compared to other alloyed $\mathrm{Fe}_{3} \mathrm{Al}$ intermetallics. A tenacious surface film was noticed in the Ti-alloyed intermetallic (figure 4). Detailed fractographic and microstructural studies of the alloyed intermetallics revealed the precipitation of brittle phases on alloying $\mathrm{Ta}, \mathrm{Mo}, \mathrm{V}, \mathrm{Nb}$ and $\mathrm{Si}$ to $\mathrm{Fe}_{3} \mathrm{Al}$ (Agarwal and Balasubramaniam 1996b). These intermetallics could, therefore, not be thermomechanically processed at high temperatures.

The specific example of $\mathrm{Ta}$ addition to iron aluminide $\mathrm{Fe}_{3} \mathrm{Al}$ is addressed below. Passivity enhancement by the addition of $\mathrm{Ta}$ is confirmed by potentiodynamic polarization behaviour of Fe-24Al-5Ta in $0.05 \mathrm{~mol} / 1 \mathrm{H}_{2} \mathrm{SO}_{4}$ solution (figure 5). The base intermetallic exhibited active behaviour in this electrolyte. The addition of Ta should result in a passive layer which could inhibit the entry of hydrogen into the iron aluminide matrix and thus prevent the degradation of mechanical properties by hydrogen. However, the Ta-alloyed iron aluminide could not be thermomechanically processed into thin strips by multi-pass rolling at $1000^{\circ} \mathrm{C}$ as it cracked after $50 \%$ deformation. In order to understand the poor thermomechanical response of the intermetallic, a detailed microstructural examination of the intermetallic was carried out. The X-ray diffraction patterns obtained from the base $\mathrm{Fe}_{3} \mathrm{Al}$ and the Ta-alloyed intermetallics were analyzed. The additional peaks in the pattern of Ta-alloyed intermetallic have been identified to belong to $\mathrm{Fe}_{5} \mathrm{Ta}_{3}$. The Fe-24Al-5Ta specimen was microstructurally examined in a scanning electron microscope and a characteristic microstructure is presented in figure $6 \mathrm{a}$. The precipitation

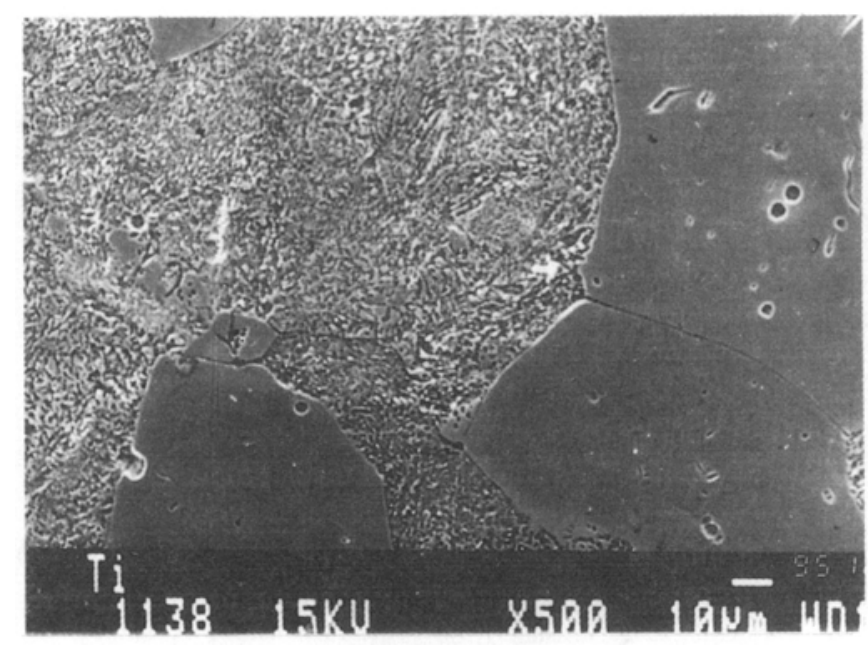

Figure 4. Tenacious surface film on the surface of $\mathrm{Fe}$ 24Al-5Ti. 
of $\mathrm{Fe}_{5} \mathrm{Ta}_{3}$ phase in the intermetallic is confirmed. The fracture morphology of these intermetallic (figure $6 \mathrm{~b}$ ) indicates that the fracture is essentially transgranular in nature with crystallographic secondary cracks. The crack propagates by cleavage and the river line markings on the fracture surface indicate that the origin of fracture was at the grain boundaries, possibly induced by the precipitates at the grain boundaries. This results in overall brittle fracture of the intermetallic. Therefore, the addition of $\mathrm{Ta}$ to $\mathrm{Fe}_{3} \mathrm{Al}$, although beneficial from passivity enhancement angle, results in poor thermomechanical response due to the brittle nature of the precipitated phase $\mathrm{Fe}_{5} \mathrm{Ta}_{3}$. Although hydrogen entry into the lattice would be restricted by the passive layer, there is no benefit to be gained because of the deleterious effect of the brittle phase precipitation. Therefore, the amount of Ta to be alloyed should be maintained below the solid solubility limit to prevent $\mathrm{Fe}_{5} \mathrm{Ta}_{3}$ precipitation.

It is important that the addition of passivity-inducing elements should not lead to brittle intermetallic precipitation. If this is taken into account, then the hydrogen embrittlement (HE) could be minimized and higher room temperature ductilities can be achieved with these alloying additions. Moreover, the element(s) would provide additional solid solution strength to the base intermetallic. For example, alloying with $\mathrm{Mo}, \mathrm{Zr}, \mathrm{Nb}, \mathrm{Ti}$ and $\mathrm{TiB}_{2}$ increases the high temperature strength of $\mathrm{Fe}_{3} \mathrm{Al}$ and FeAl (Liu and Kumar 1993).

\subsection{Irreversible hydrogen traps}

It is well known that certain elements/compounds when present in alloys act as trap sites for hydrogen. Traps

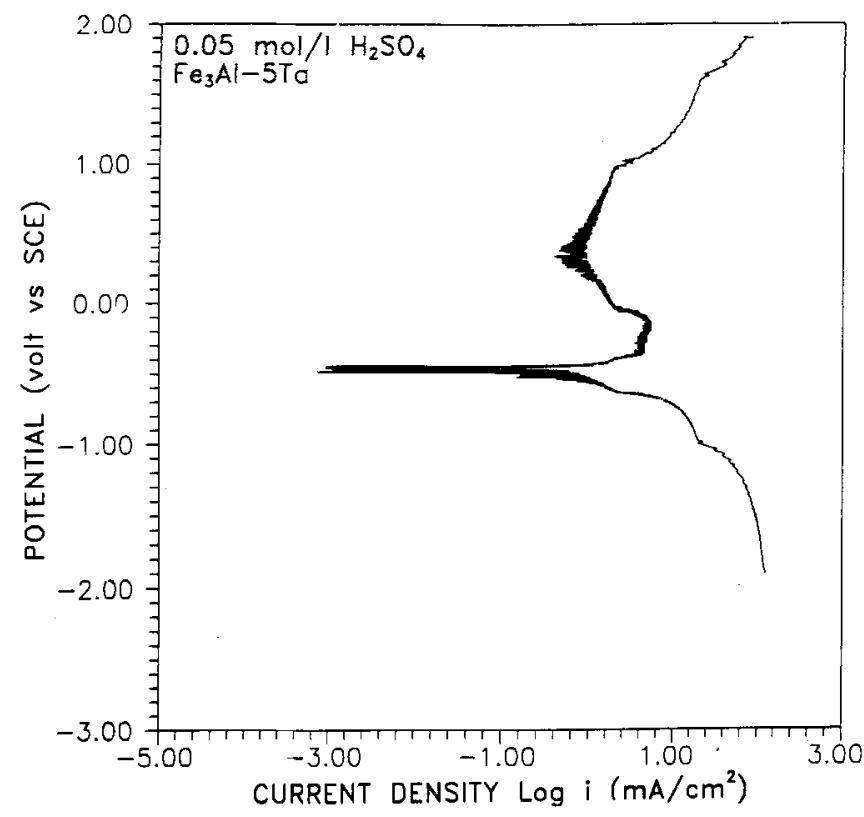

Figure 5. Potentiodynamic polarization curve for $\mathrm{Fe}-24 \mathrm{Al}-5 \mathrm{Ta}$ in $0.05 \mathrm{~mol} / 1 \mathrm{H}_{2} \mathrm{SO}_{4}$ solution using a scan rate of $1 \mathrm{mV} / \mathrm{s}$. can be classified as either reversible or irreversible based on the binding energy of traps with hydrogen. For example, $\mathrm{Ti}$ in steels acts like a reversible trap while incoherent $\mathrm{TiC}$ precipitates in steels are irreversible traps (due to trapping at the inclusion/matrix interface) (Pressouyre 1979). If the irreversible traps are finely and homogeneously distributed throughout the matrix, there is a good likelihood that hydrogen would be irreversibly trapped at these sites and hydrogen cannot accumulate at critical regions to cause embrittlement. Therefore, addition of elements which can act as irreversible traps for hydrogen could also be envisaged to improve the ductility of iron aluminides. However, this may not be promising route because there would be sufficient accumulation of hydrogen, with time, at these locations and once the hydrogen concentration exceeds the critical concentration for embrittlement, the material would be susceptible to embrittlement. It should

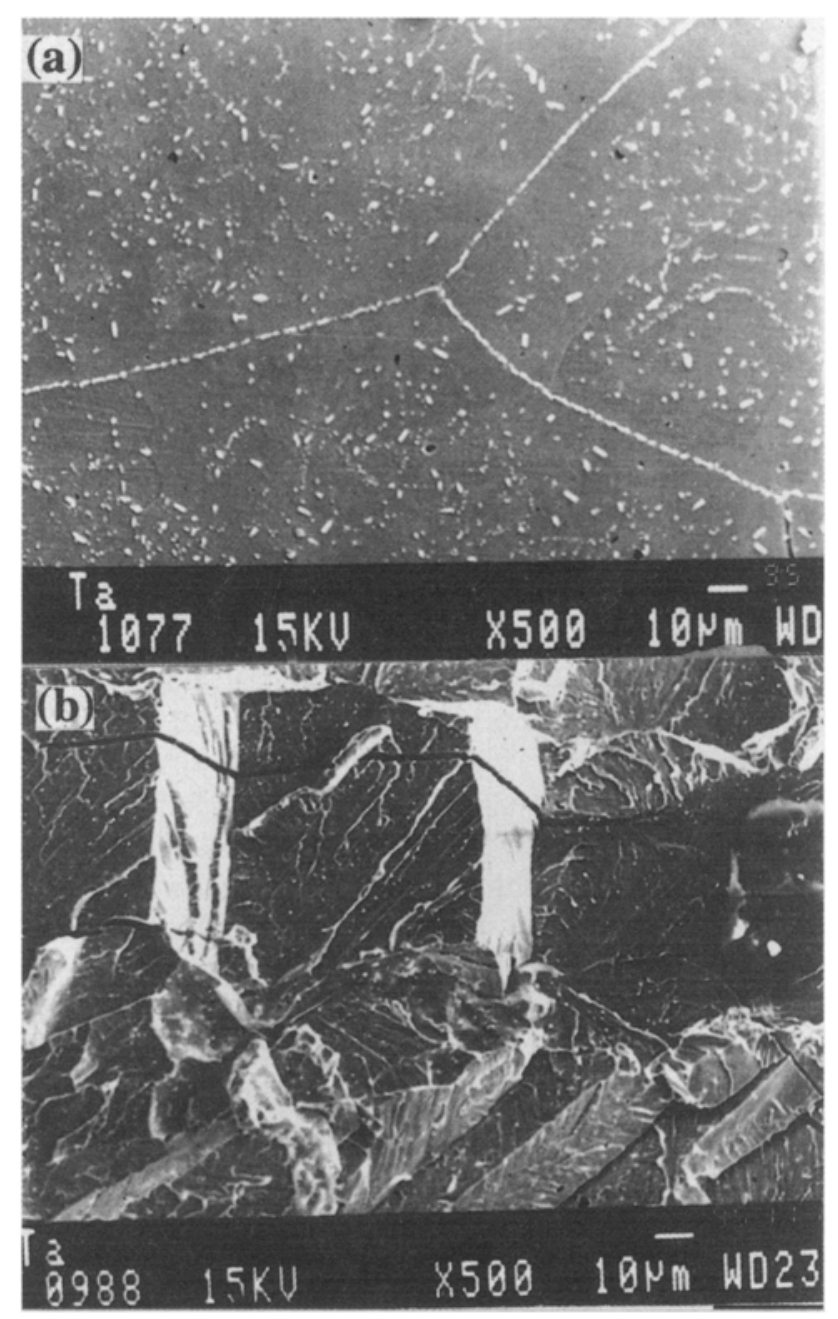

Figure 6. Scanning electron micrographs of (a) the Fe-24Al5 Ta intermetallic showing the presence of precipitates and (b) the fracture surface showing transgranular failure with crystallographic secondary cracks. 
be noted that hydrogen appears to be generally trapped reversibly in both Fe-25Al (Kasul and Heldt 1991) and $\mathrm{Fe}-35 \mathrm{Al}$ (Kasul and Heldt 1993) based on the reversible nature of embrittlement (i.e. recovery of ductility on baking treatments). The improvement in ductility on $\mathrm{C}$ addition to iron aluminide (Baligdad et al 1997) must be related to irreversible hydrogen trapping at the $\mathrm{Fe}_{3} \mathrm{AlC}$ precipitates.

\subsection{Addition of oxygen active elements}

It has been recently reported that addition of $0.15 \% \mathrm{Ce}$ to iron aluminides leads to a significant increase in ductility (Yangshan et al 1996), although the reason for the effect has not yet been clearly understood. The same study also indicated that the grain boundaries contained an intermetallic phase rich in $\mathrm{Ce}$ and $\mathrm{Fe}$. One possibility for the enhancement in ductilities due to $\mathrm{Ce}$ addition could be the irreversible trapping of hydrogen at the Ce-containing phase, thereby minimizing embrittlement. Interestingly, the addition of $\mathrm{Ce}$ had also changed the composition of the surface passive film. With the addition of $\mathrm{Ce}$, the surface layer contained a larger amount of $\mathrm{Al}_{2} \mathrm{O}_{3}$ and $\mathrm{Cr}_{2} \mathrm{O}_{3}$ and a lower amount of $\mathrm{Fe}_{2} \mathrm{O}_{3}$ than the $\mathrm{Fe}-28 \mathrm{Al}-2 \mathrm{Cr}$ alloy without $\mathrm{Ce}$ addition. Therefore, the presence of oxygen active element $\mathrm{Ce}$ does have a strong effect on the nature of the scale formed on the surface of the material and this would affect hydrogen liberation rates as well as hydrogen diffusion through the surface layer. Another effect noticed with the addition of $\mathrm{Ce}$ was that the recrystallized grain size was much finer, which resulted in a concomitant increase in strength. The grain size would also play a role in the diffusion of hydrogen through the material although its relative significance is not known at present. Grain size also affects the strength of iron aluminides. $\mathrm{Fe}-25 \mathrm{Al}$ was found to obey Hall-Petch rule (Agarwal and Balasubramaniam 1997).

In view of the beneficial effect of $\mathrm{Ce}$ addition on the mechanical properties, we added $\mathrm{Mm}$ (a mixture of rare-earth elements with the major constituent being $\mathrm{Ce}$ ) in $\mathrm{Cr}$ - and Ti-alloyed iron aluminides. The processing route described above in the case of the alloyed iron aluminides was similarly employed in this case. The rolled specimens did not exhibit any ductility and this was explained on the basis of segregation of the elements that constituted $\mathrm{Mm}$ to the grain boundaries of the aluminide, thereby weakening them (Banerjee and Balasubramaniam 1998a). Moreover, precipitation of additional phases rich in $\mathrm{Al}, \mathrm{Ce}$ and $\mathrm{Fe}$ was also noticed on some cleavage planes. Therefore, addition of $\mathrm{Mm}$ was not successful in inducing ductility. Critical control of $\mathrm{Mm}$ (or the oxygen active element) addition is therefore crucial to impart ductility. We simultaneously undertook a detailed study of the effect of $\mathrm{Mm}$ additions on the aqueous corrosion and high temperature oxidation behaviour of the iron aluminides. Some interesting results of this study are summarized below.

The potentiodynamic polarization curves for $\mathrm{Fe}-25 \mathrm{Al}$, $\mathrm{Fe}-28 \mathrm{Al}$, and $\mathrm{Fe}-28 \mathrm{Al}-2 \mathrm{Cr}$, with and without $\mathrm{Mm}$ addition, in $0.05 \mathrm{~mol} / 1 \mathrm{H}_{2} \mathrm{SO}_{4}$ solution are presented in figure 7 (Babu 1998). It is interesting to note that the $\mathrm{Fe}-28 \mathrm{Al}$ intermetallic shows a distinct active-passive transition where it is not clear in the case of Fe-25Al. This could probably be the reason why the latter is more ductile compared to the former. The Cr-alloyed aluminides also exhibit active-passive behaviour. Addition of $\mathrm{Mm}$ has resulted in a decrease in the passive current density, with the other parameters remaining almost similar to the $\mathrm{Cr}$-alloyed intermetallic. This implies that $\mathrm{Mm}$ additions have a beneficial effect by modifying the passive layer on the iron aluminide. Therefore, addition of oxygen active elements are beneficial to the passivation properties of the iron aluminides. $\mathrm{Mm}$ addition also improved the passive film formation properties of the Ti-alloyed iron aluminides (Babu 1998; Banerjee and Balasubramaniam 1999). The effect of these additions on the high temperature oxidation of iron

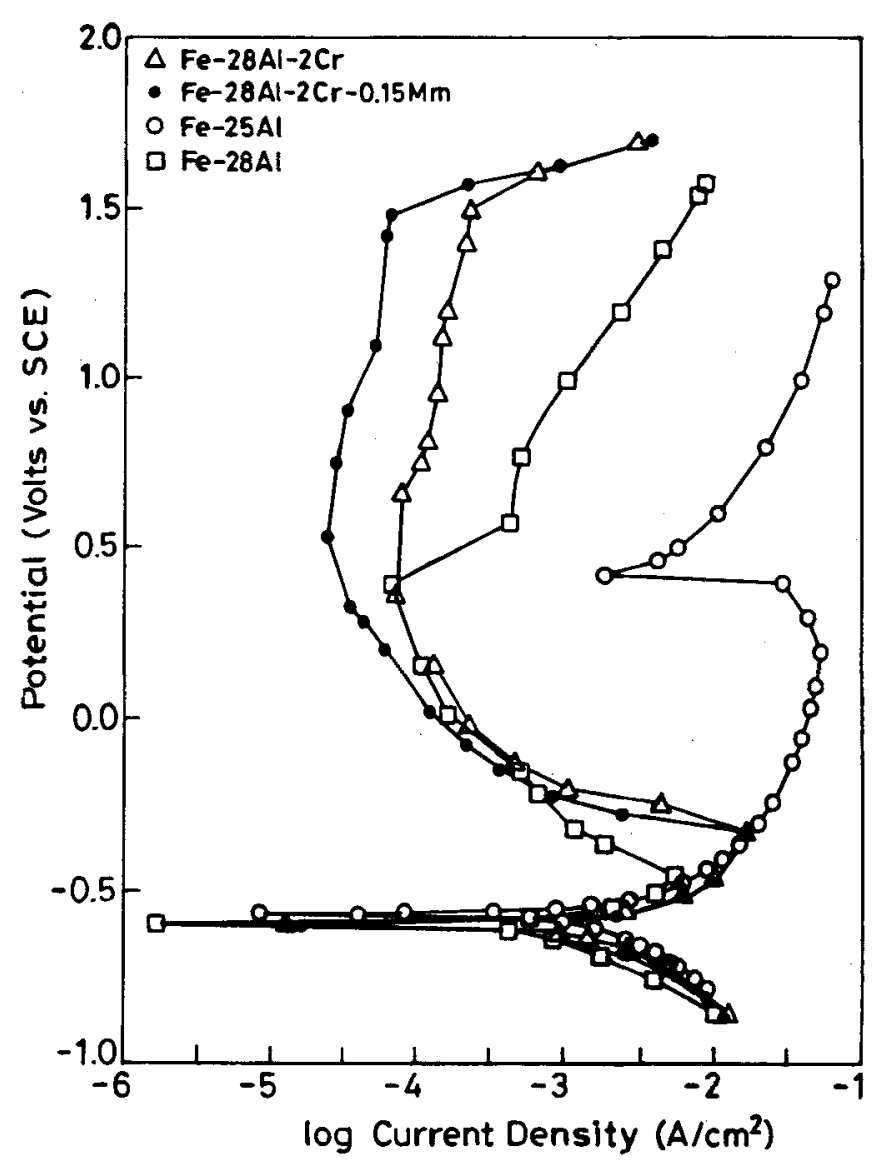

Figure 7. Potentiodynamic polarization curves for $\mathrm{Fe}-25 \mathrm{Al}$, $\mathrm{Fe}-28 \mathrm{Al}, \mathrm{Fe}-28 \mathrm{Al}-2 \mathrm{Cr}$ and $\mathrm{Fe}-28 \mathrm{Al}-2 \mathrm{Cr}-0.15 \mathrm{Mm}$ in $0.5 \mathrm{~mol} / 1$ $\mathrm{H}_{2} \mathrm{SO}_{4}$ solution using a scan rate of $1 \mathrm{mV} / \mathrm{s}$. 
aluminides was also studied. It was earlier reported by Smialek et al (1988) that the addition of oxygen active elements like $\mathrm{Hf}, \mathrm{Zr}$ and $\mathrm{B}$ in iron aluminide ( $\mathrm{Fe}-40 \mathrm{Al}$ ) resulted in slight improvements in the isothermal and cyclic oxidation behaviour. We studied the effect of $\mathrm{Mm}$ addition on the isothermal oxidation behaviour of $\mathrm{Fe}-28 \mathrm{Al}-\mathrm{Cr}$. The weight gain curves for $\mathrm{Fe}-28 \mathrm{Al}$, $\mathrm{Fe}-28 \mathrm{Al}-2 \mathrm{Cr}$ and $\mathrm{Fe}-28 \mathrm{Al}-2 \mathrm{Cr}-0.15 \mathrm{Mm}$ after oxidation in pure oxygen at a temperature of $1330 \mathrm{~K}$ in figure 8 indicate that parabolic kinetics were followed (Babu 1998). The parabolic rate constant can be determined from the slopes of the plots provided in figure 8 . The oxidation resistance of $\mathrm{Fe}-28 \mathrm{Al}-2 \mathrm{Cr}$ is lower than that of $\mathrm{Fe}-28 \mathrm{Al}$ and this is due to the fast rate of oxidation in the initial stage for the $\mathrm{Cr}$-alloyed intermetallic when compared with Fe-28Al. This can be easily understood by analyzing the instantaneous rate constant $\left(k_{\mathrm{p}}^{\mathrm{i}}\right)$ of the various alloys which is provided in figure 9 (Babu 1998). The instantaneous rate constant can be determined by mathematical analysis of the weight gain curves (Roy et al 1996). On alloying with $\mathrm{Mm}$, the initial rapid rate was not observed in the $\mathrm{Cr}$-alloyed intermetallic and the oxidation rate of the $\mathrm{Cr}$-alloyed aluminide with $\mathrm{Mm}$ was comparable to that of $\mathrm{Fe}-28 \mathrm{Al}$. This clearly brings out

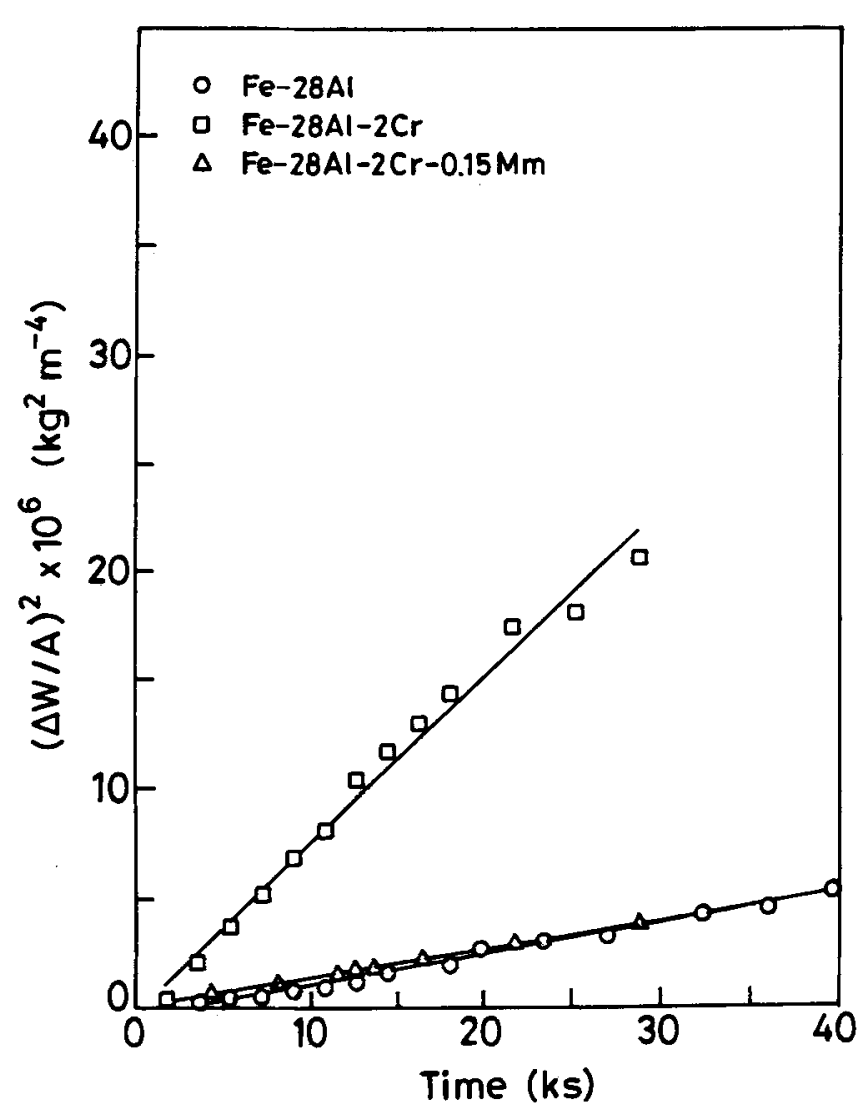

Figure 8. Isothermal oxidation weight gain curves for $\mathrm{Fe}-25 \mathrm{Al}$, $\mathrm{Fe}-28 \mathrm{Al}-2 \mathrm{Cr}$ and $\mathrm{Fe}-28 \mathrm{Al}-2 \mathrm{Cr}-0.15 \mathrm{Mm}$ at $1330 \mathrm{~K}$ in pure oxygen. Notice that oxidation behaviour obeys parabolic kinetics. the beneficial effect of addition of $\mathrm{Mm}$ on the high temperature oxidation of iron aluminides. The addition of oxygen active elements, especially rare earth elements, in optimum amounts, leads to improved scale adhesion and resistance to oxidation (Moon 1989). In aluminides, rare earth additions are believed to decrease the stress concentration at the metal-oxide interface and consequently reduce the convolution and spallation (Prescott and Graham 1992). A tentative proposal for the increased oxidation resistance of the $\mathrm{Mm}$-alloyed intermetallic is that the segregated rare earths at the grain boundaries (Banerjee and Balasubramaniam 1998a) can influence oxidation by pegging, with the rare earth oxide dispersoids acting like pegs (Babu 1998). Mm additions therefore also affect the high temperature environmental degradation behaviour. Interestingly, it was also observed that the addition of these elements which had segregated to the grain boundaries in the iron aluminides also retarded the diffusivity of hydrogen (Banerjee and Balasubramaniam 1998b), thereby showing that there is a certain amount of irreversible hydrogen trapping also associated with $\mathrm{Mm}$ addition.

It has been reported recently that addition of small amounts of $\mathrm{B}$ and $\mathrm{Zr}$ were very beneficial to the ductility

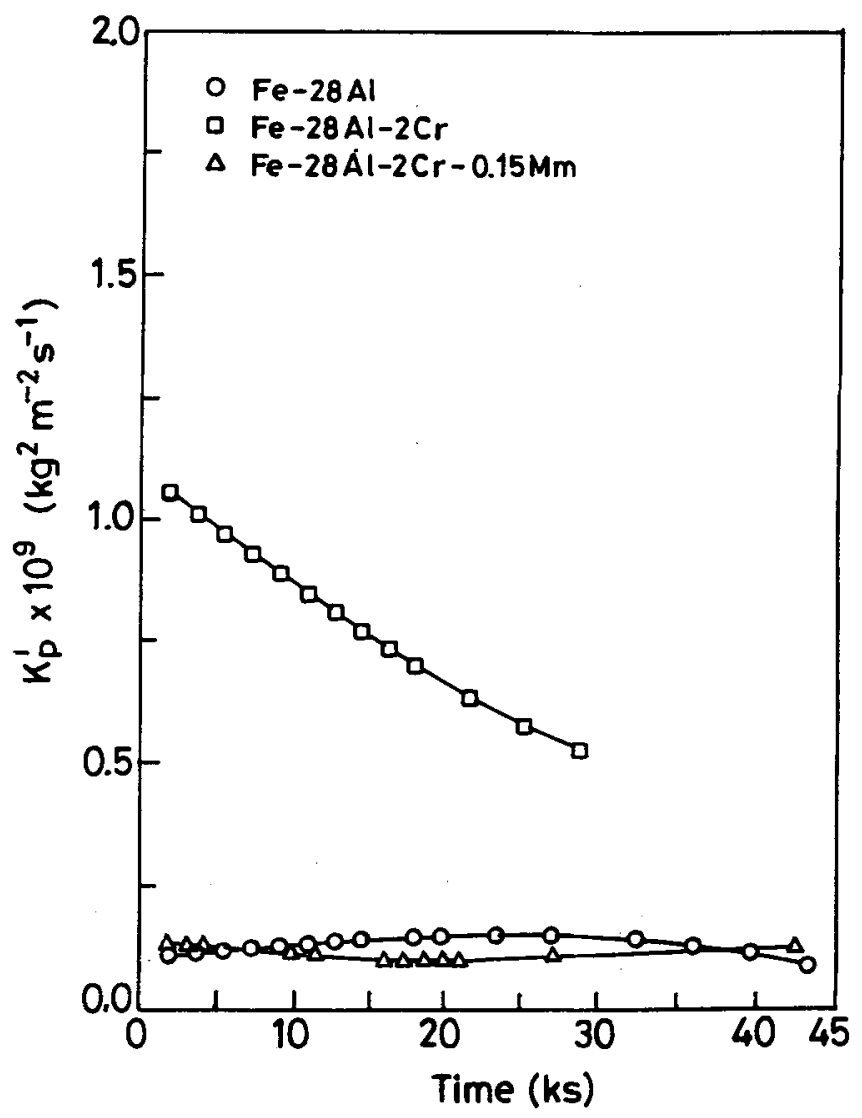

Figure 9. Instantaneous rate constant as a function of oxidation time for $\mathrm{Fe}-25 \mathrm{Al}, \mathrm{Fe}-28 \mathrm{Al}-2 \mathrm{Cr}$ and $\mathrm{Fe}-28 \mathrm{Al}-2 \mathrm{Cr}-0.15 \mathrm{Mm}$ at $1330 \mathrm{~K}$ in pure oxygen. 
of iron aluminides (Broglio and Stoloff 1997). The microstructure of the alloy plays an important role in enhancing the ductility of these alloys and only under certain heat treatment conditions, does the enhanced ductilities obtain with the addition of $\mathrm{B}$ and $\mathrm{Zr}$ ( $\mathrm{Liu}$ and Stoloff 1998). The beneficial role of alloying these elements has not yet been specifically understood. Choi et al (1997) have shown that $\mathrm{Zr}$ additions were beneficial to the cyclic oxidation resistance while Smialek et al (1988) reported that $\mathrm{Hf}$ additions were better than $\mathrm{Zr}$ additions. Interestingly, $\mathrm{B}$ additions, like $\mathrm{TiB}_{2}$ additions, cause hot cracking and reduces the weldability while $C$ additions are beneficial in this regard (Liu and Kumar 1993). The behaviour of iron aluminides containing $C$ has been recently studied by Baligdad et al (1997).

There is a lot of scope, therefore, for tailoring the iron aluminide by the addition of oxygen active elements and by this process obtain a surface layer that is advantageous as regards hydrogen liberation rate and hydrogen entry are concerned. It is envisaged that the addition of these elements should be pursued with greater zeal in order to reduce the embrittling effect of hydrogen on these materials.

\subsection{Recrystallization inhibition}

Alloying additions to iron aluminide could also be added for preventing recrystallization during high temperature stress-relieving annealing treatments, which are generally carried out after severe deformation processing. The HE susceptibility is lower for a stress-relieved unrecrystallized structure (McKamey and Pierce 1993). This has been hypothesized to be due to the recrystallized grains disrupting the diffusion of hydrogen (McKamey and Pierce 1993). A possible reason for enhancement of ductility due to the unrecrystallized structure could be the reduction in dislocation density during stress relief annealing treatment. The gliding $a\langle 111\rangle$ dislocations in $\mathrm{Fe}_{3} \mathrm{Al}$ are composed of two $a / 2\langle 111\rangle$ partials joined by an anti phase boundary (Baker et al 1991). Hydrogen is transported primarily by these partial dislocations deep down into the material. Further, the partial dislocations can be locked as immobile $a\langle 100\rangle$ dislocations by the Friedel mechanism. It has been shown that hydrogen promotes the formation of locked $\langle 100\rangle$ dislocation and twice the normal amount of hydrogen can be absorbed by these locked dislocations ( $\mathrm{Li}$ and $\mathrm{Liu}$ 1992). According to all theories of hydrogen embrittlement, the concentration of hydrogen should exceed a critical amount to cause embrittlement and this critical concentration is achieved in the $\{100\}$ planes due to the above reason (Balasubramaniam 1996). Once the critical concentration is achieved, hydrogen causes decohesion of the matrix and this is verified by cleavage fracture observed in this class of iron aluminides (Agarwal and Balasubramaniam 1996b). Moreover, etch-pit studies have indicated that the cleavage facets are of the $\{100\}$ type (Agarwal et al 1996a), further confirming the above mechanism. The improvement in ductility upon stress relieving the microstructure could therefore be due to the reduction in the number of $a / 2\langle 111\rangle$ dislocations in the structure during the annealing treatment. With a lower amount of $a / 2\langle 111\rangle$ partials in the microstructure, the local accumulation of hydrogen and the locking of partials would be less severe and hence this would result in some ductility, as observed experimentally (McKamey and Pierce 1993; Agarwal et al 1996a).

There is a sacrifice in strength upon the recrystallization treatment. Complete recrystallization leads to a large decrease in strength (McKamey and Pierce 1993) and therefore, not an viable alternative. The exception to the above would be when the alloying addition produces a fine grain size after the recrystallization anneal in which case the strength would not decrease drastically. Interestingly, $\mathrm{Ce}$ additions to iron aluminide produce a fine grained recrystallized structure unlike the large grain size obtained for the iron aluminide without $\mathrm{Ce}$ addition. There is no degradation of strength for the Ce-alloyed iron aluminide even in the recrystallized condition (Yangshan et al 1996). Mm additions also produce a fine grained structure after recrystallization (Banerjee and Balasubramaniam 1998a). Therefore, the addition of elements to inhibit recrystallization would also be beneficial in improving the room temperature strength and ductility of iron aluminides.

\section{Conclusions}

Environmental effects in iron aluminide have been reviewed. The importance of hydrogen liberation rates on the surfaces of iron aluminide in determining their embrittling behaviour has been described. Experimental verification for the role of hydrogen liberation rates on the HE behaviour has also been provided and discussed. The alloy development efforts to produce ductile iron aluminides are outlined. Induction of passivity in the iron aluminides is advantageous in minimizing HE. However, the alloying additions should not be added above the solid solubility limit as otherwise the material is inherently brittle due to the precipitation of brittle ternary phases. The role of oxygen active elements in affecting $\mathrm{HE}$ behaviour has also been addressed. The addition of such elements is generally advantageous for corrosion and high temperature oxidation. Finally, the mechanism of $\mathrm{HE}$ in iron aluminides has been discussed while addressing the role of the microstructure in affecting embrittlement. It is also envisaged that addition of elements that prevent complete recrystallization would be beneficial to the ductility of iron aluminides. 


\section{References}

Agarwal A and Balasubramaniam R 1996a Bull. Mater. Sci. 19 91

Agarwal A and Balasubramaniam R 1996b Practical Metallography 33453

Agarwal A and Balasubramaniam R 1997 J. Mater. Sci. Lett. 16469

Agarwal A, Balasubramaniam R and Bhargava S 1996a Metall. Mater. Trans. A27 2985

Agarwal A, Akhtar M J and Balasubramaniam R 1996b J. Mater. Sci. 315207

Babu N 1998 Room temperature aqueous corrosion and high temperature oxidation behaviour of iron aluminides, Master of Technology Thesis Indian Institute of Technology, Kanpur

Baker I, Nagpal P, Liu F and Munroe P 1991 Acta Metall. 39 1637

Balasubramaniam R 1996 Scr. Mater. 34127

Balasubramaniam R 1997 J. Alloys Compds. 253-254 203

Baligdad R G, Prakash U, Radhakrishna A, Rao V R, Rao P K and Ballal N B 1997 Scr. Mater. 36667

Banerjee P and Balasubramaniam R 1997 Bull. Mater. Sci. 20713

Banerjee P and Balasubramaniam R 1998a Scr. Mater. 381143

Banerjee P and Balasubramaniam R 1998b Scr. Mater. 391215

Banerjee P and Balasubramaniam R 1999 Trans. IIM. (in press)

Broglio M and Stoloff N S 1997 Scr. Mater. 37329

Choi S C, Kim S H, Lee D B and Park H S 1997 J. Korean Inst. Met. Mater. 35145

Kasul D B and Heldt L A 1991 Scr. Metall. Mater. 251047

Kasul D B and Heldt L A 1993 Metall. Trans. A25 1285

Lee K J, Lukowski J T and White C L 1996 Scr. Mater. 35 1153
Liu C T and George E P 1990 Scr. Metall. Mater. 241285

Li J C M and Liu C T 1992 Scr. Metall. Mater. 271701

Liu C T and Kumar K S 1993 J. Metals 4538

Liu C T and Stoloff N S 1998 Scr. Mater. 38341

Liu C T, Lee E H and McKamey C G 1989 Scr. Metall. 23 875

Liu C T, McKamey C G and Lee E H 1990 Scr. Metall. Mater. 24385

McKamey C G and Liu C T 1990 Scr. Metall. Mater. 24 2119

McKamey C G and Pierce D H 1993 Scr. Metall. Mater. 28 1173

McKamey C G and Liu C T 1996 Scr. Mater. 351071

McKamey C G, Horton J A and Liu C T 1988 Scr. Metall. 221679

Moon D P 1989 Mater. Sci. Technol. 5754

Mukherjee S and Balasubramaniam R 1996 Bull. Mater. Sci. 19831

Prescott R and Graham M J 1992 Oxid. Metals 3873

Pressouyre G M 1979 Acta Metall. A10 1571

Roy T K, Balasubramaniam R and Ghosh A 1996 Metall. Mater. Trans. A27 3993

Sikka V K 1994 in Processing, properties and applications of iron aluminides (eds) $\mathrm{J} \mathbf{H}$ Schneibel and $\mathrm{M}$ A Crimp (Warrendale: TMS) p. 3

Smialek J L, Doychak J and Gaydosh D J 1988 in Oxidation of high temperature intermetallics (eds) $\mathrm{T}$ Grobstein and $\mathrm{J}$ Doychak (Warrendale: TMS) p. 83

Stoloff N S and Duquette D J 1990 J. Metals 4530

Tu J P, Meng L and Liu M S 1998 Scr. Mater. 38833

Yangshan S, Zhengjun Y, Zhonghua Z and Haibo H 1996 Scr. Mater. 33811 